\title{
APPLICATION OF GPR AND FWD IN ASSESSING PAVEMENT BEARING CAPACITY
}

Josipa Domitrović, MCE, University of Zagreb, Faculty of Civil Engineering, Department of Transportation, e-mail: jdomitrovic@grad.hr

Tatjana Rukavina, PhD.Prof., MCE, University of Zagreb, Faculty of Civil Engineering, Department of Transportation, e-mail: rukavina@grad.hr

\section{Abstract}

The process of pavement maintenance and rehabilitation starts by collecting the data which will form the base for evaluation of pavement functional and structural condition. Collection of data can be performed by destructive and non-destructive testing. Usually preferred are the non-destructive methods, that do not damage the pavement, and the process of pavement evaluation is objective and repeatable. Non-destructive testing methods are becoming more and more popular, especially for assessing the structural condition of the pavement. Non-destructive testing by a Falling Weight Deflectometer (FWD) and the analysis of so collected data by the process of backcalculations is today the usual tool for assessing pavement bearing capacity. One of the basic input parameters for analysis of the data collected by FWD is pavement layers thickness.

The practice in Croatia is to determine pavement layers thickness by coring. This destructive method affects pavement integrity, so the number of such tests should be kept to the minimum. By coring the accurate thickness of all pavement layers is obtained on specific point locations. Thus, numerous deviations in layer thickness remain unnoticed, and in the end, use of such data for the process of backcalculations does not provide ac urate values of layer moduli. Coring can be replaced with non-destructive method of testing by Ground Penetrating Radar (GPR), which provides continuous information on thickness of all pavement layers.

The paper shows the method for assessing the bearing capacity of the pavement based on the data collected by FWD, GPR and coring. The calculation for layer moduli was performed by the ELMOD software, separately for the layers thickness data obtained by coring, and separately for the thickness obtained by GPR tests. Analysis and comparison of the results of calculated elasticity moduli obtained by using various methods for collecting layer thickness data were performed in the paper.

Keywords: non-destructive testing, FWD, GPR, layer thickness, elastic moduli 


\section{INTRODUCTION}

Road is capital investment whose value is gradually reduced within its lifetime by progression of degradation processes. Pavement degradation can be slow down or stopped by applying appropriate maintenance and rehabilitation techniques and for that it is necessary to evaluate pavement structural condition, i.e. bearing capacity. Nowdays, most common method for determining pavement bearing capacity is deflection measurement, mostly by Falling Weight Deflectometer (FWD). FWD determines the full dynamic deflection bowl by applying known impulse loads on the pavement. Pavement deflections are then analysed using backcalculation procedure for determing the layer elastic moduli. The reliability of estimated pavement moduli depends on the accuracy of layer thickness data.

In Croatia, thickness data is usually obtained from project documentation or coring. Each of these methods has its advantages and disadvantages. Data collection based on project documentation is fast and requires minimum effort but is not very reliable. Coring provides most accurate thickness data, but is expensive, time consuming, has significant impact on traffic and affects pavement integrity so the number of such tests should be keep on minimum. Furthermore, data is obtained only on selected locations that may not be representative for considered road section so deviations in pavement structure could easily be missed. This will provide incorrect information for further analysis and can lead to application of wrong maintenance and/or rehabilitation techniques.

To address issues mentioned above Ground Penetrating Radar (GPR) was introduce as non-destructive, fast and reliable technique that provides a continuous display of pavement layers thickness. Evaluation studies carried out in the last 20 years show that deviations between GPR and core thickness results of newly constructed pavement range from $2 \%$ to $5 \%$ of total thickness [1] and for old pavements are mostly less than 10\% [2]. Based on this it can be conclude that GPR is suitable non-destructive technique, which can replace coring.

\section{DESCRIPTION OF GPR AND FWD METHODS}

Though, integration of non-destructive testing devices, FWD and GPR for pavement evaluation is not new technology most pavement engineers in Croatia are not aware of their advantages and still rely on traditional destructive methods like coring to obtained necessary pavement data. In continuation, components and basic operating principles of GRP and FWD are explained. 


\subsection{Ground Penetrating Radar (GPR)}

The GPR device used in road surveys is vehicle mounted system that normally consists of following components: 1) antennas (air or ground coupled) with transmitter and receiver, 2) GPR control/acquisition unit, 3) PC for data collection and 4) positioning device (Figure 1, left).
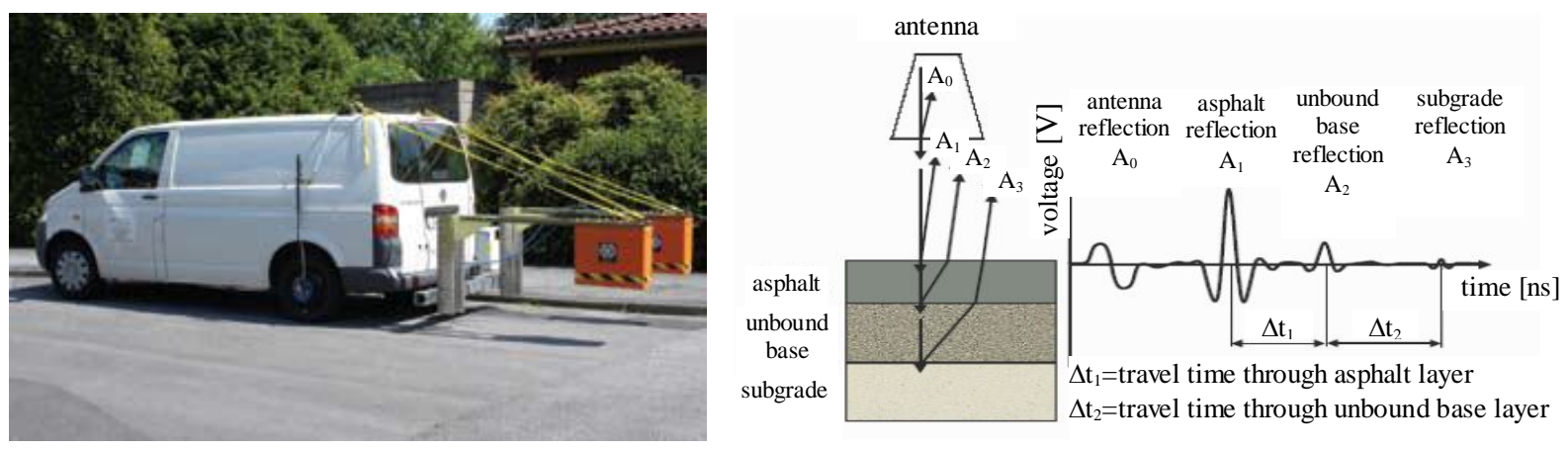

Figure 1. Ground Penetrating Radar (left); Shematic representation of EM signal (right)

The GPR system is base on the radar principle in which the antenna transmits pulses of radar energy, i.e. electromagnetic (EM) waves with a central frequency varying from $10 \mathrm{MHz}$ up to $2.5 \mathrm{GHz}$ [3] into the pavement. EM waves partly reflect and partly pass through layers of materials with different EM characteristics. A part of energy that reflects at layers interface is receive by GPR system and displayed as a plot of amplitude (voltage) and time necessary for its return to antenna (Figure 1, right) [2].

The speed of passing EM wave through a particular material is under the influence of its relative dielectric constant $\left(\varepsilon_{\mathrm{r}}\right)$. For asphalt pavements materials relative dielectric constants can be calculated using surface reflection method.

Once the values of materials relative dielectric constants are calculate it is possible to determine thickness of a particular layer $\left(h_{i}\right)$ using equation (1) [4]:

$$
\mathrm{h}_{\mathrm{i}}=\frac{\mathrm{c} \Delta \mathrm{t}_{\mathrm{i}}}{\sqrt{\varepsilon_{\mathrm{r}}}}
$$

where: $c-$ speed of EM wave through vacuum

$\Delta t_{i}-$ time between amplitudes $A_{i}$ and $A_{i+1}$

$\varepsilon_{\mathrm{r}}$ - relative dielectric constant of the material.

EM signal, shown in Figure 1, right, can be send up to 1000 scans/second [3]. Given that during the measurement vehicle moves along the road, we get 
continuous display of the EM wave's reflection, the interpretation of which determines pavement layers thickness.

\subsection{Falling Weight deflectometer (FWD)}

The FWD device for pavement evaluation is trailer mounte system towed by the vehicle (Figure 2, left). Basic components of a typical FWD unit are: 1) control system for data collection, processing and storing, 2) loading weight and plate, 3) hydraulic system and 4) geophones.
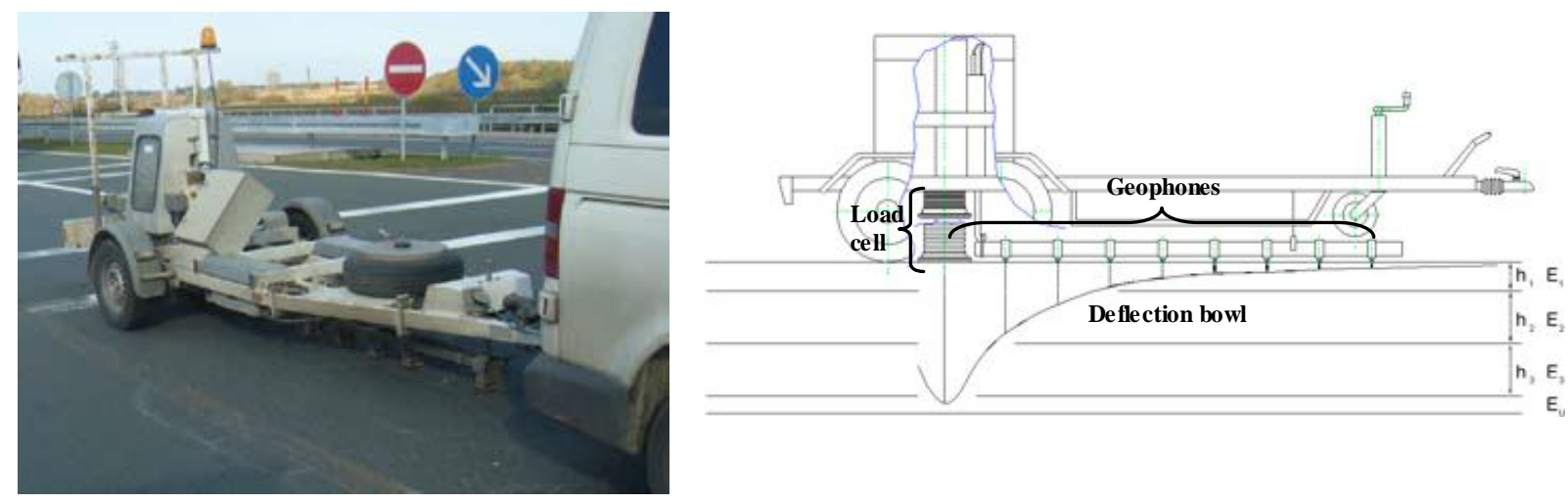

Figure 2. Falling Weight Deflectometer (left); Schematic representation of FWD operation (right)

The FWD applies stationary dynamic load, similar to a passing wheel load, onto the pavement surface. The FWD generates a load pulse by dropping weight onto $300 \mathrm{~mm}$ diameter circular load plate. By varying the mass and/or drop height, impulse load can be varied between $10 \mathrm{kN}$ to $120 \mathrm{kN}$ [5]. Usually target peak load is $50 \pm 5 \mathrm{kN}$ which matches the standard wheel load. The pavement responses to applied load pulse are vertical deformations in a shape of deflection bowl (Figure 2, right). Deformations are measure by geophones located in the load centre and at several radial distances from the load centre.

Base on the force applied to the pavement and the shape of deflection bowl, it is possible to estimate the in-situ elastic moduli of the different pavement layers by the iterative process of backcalculation. In this process, the deflection values are first calculated for assumed elastic moduli values and compared with deflection values measured by FWD, and accordingly the assumed moduli values are further adjust for next iteration. The iteration stops once predetermined level of tolerance between calculated and measured deflection have been reach (Figure 3) [6]. 


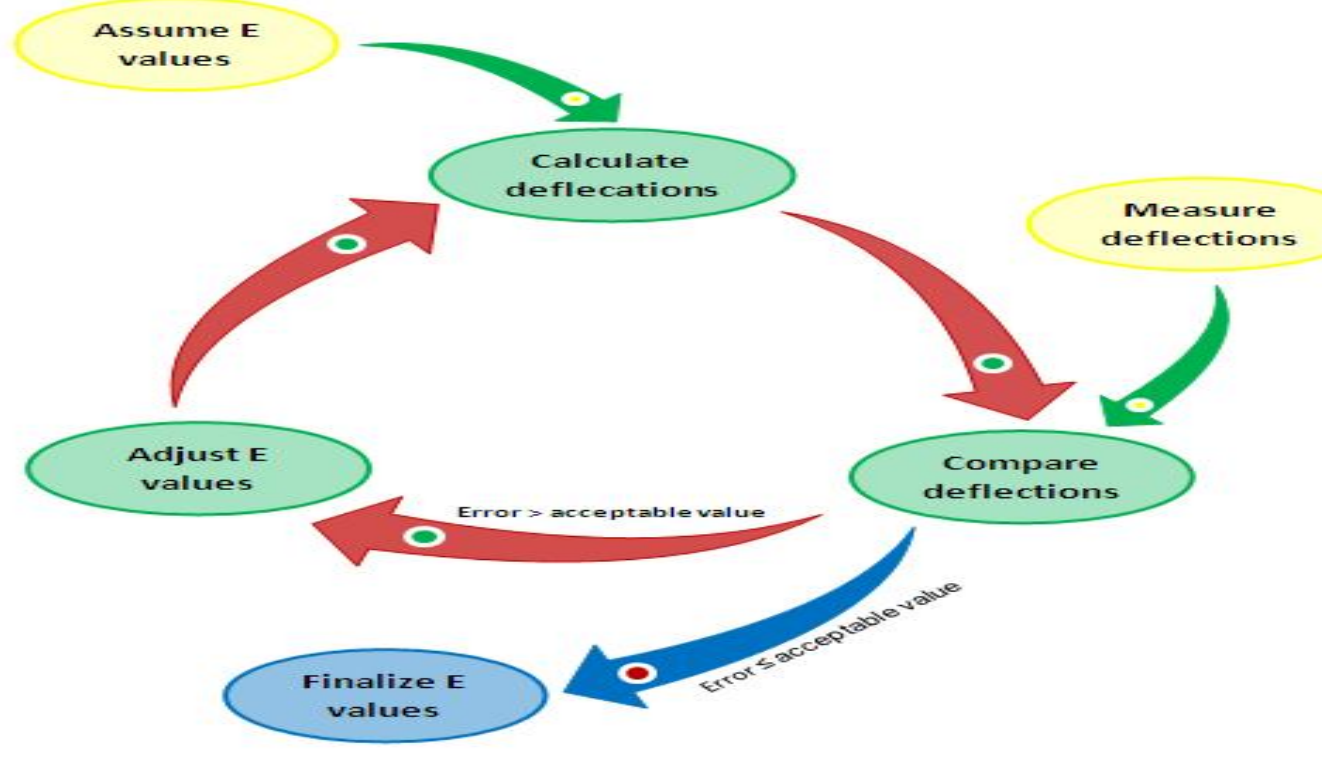

Figure 3. Shematic diagram of backcalculation process

\section{RESULTS OF FIELD TEST ON HIGHWAY A4}

A pavement investigation carried out on a section of highway A4, ZagrebGoričan from chainage $\mathrm{km} 83+000$ to $\mathrm{km} 75+500$, in the right wheel path of the drive lane. The pavement investigation involved determination of pavement deflection by FWD and pavement layers thickness by extraction of cores and GPR measurements. Based on cumulative difference method test section was divided into six homogeneous subsections (Table 1).

Table 1. Division of test section into homogeneous subsections

\begin{tabular}{|l|c|c|c|c|c|c|}
\hline $\begin{array}{l}\text { Homogeneous } \\
\text { subsection }\end{array}$ & 1 & 2 & 3 & 4 & 5 & 6 \\
\hline Chainage $[\mathrm{km}]$ & $\begin{array}{c}75+500 \\
-\end{array}$ & $\begin{array}{c}76+001 \\
-\end{array}$ & $\begin{array}{c}78+500 \\
-\end{array}$ & $\begin{array}{c}80+201 \\
-\end{array}$ & $\begin{array}{c}81+000 \\
-\end{array}$ & $\begin{array}{c}82+001 \\
-\end{array}$ \\
& $76+001$ & $77+224$ & $79+801$ & $81+000$ & $82+001$ & $83+001$ \\
\hline
\end{tabular}

\subsection{Core data}

Six cores $(\varnothing 100 \mathrm{~mm})$ were extracted on selected locations from each homogeneous subsection to determine pavement layers thickness. Due to damage of cement treated base layer, which on some locations is completely destroied, only the cores of asphalt surface and base layers were extracted. Determinate thickness values are shown in Table 2. 
ROMANIAN JOURNAL

OF TRANSPORT INFRASTRUCTURE

Josipa Domitrović, Tatjana Rukavina

Application of GPR and FWD in assessing pavement bearing capacity

Table 2. Asphalt layers thickness data obtained by coring Thickness [mm]

\begin{tabular}{|l|c|c|c|c|c|c|}
\hline Chainage $[\mathbf{k m}]$ & $\mathbf{7 5 + 9 0 0}$ & $\mathbf{7 6 + 9 0 0}$ & $\mathbf{7 9 + 5 0 0}$ & $\mathbf{8 0 + 3 0 0}$ & $\mathbf{8 1 + 8 0 0}$ & $\mathbf{8 2 + 7 0 0}$ \\
\hline Asphalt surface & 50 & 49 & 63 & 58 & 59 & 61 \\
\hline Asphalt base & 86 & 65 & 99 & 90 & 97 & 105 \\
\hline Total & $\mathbf{1 3 6}$ & $\mathbf{1 1 4}$ & $\mathbf{1 6 2}$ & $\mathbf{1 4 8}$ & $\mathbf{1 5 6}$ & $\mathbf{1 6 6}$ \\
\hline
\end{tabular}

\subsection{GPR data}

GPR measurements were done with two GSSI air-horn antennas, one 2,2 $\mathrm{GHz}$ and other 1,0 GHz. Measurements ware taken continuously for the hole section at vehicle speed between 50 and $70 \mathrm{~km} / \mathrm{h}$ and with signal speed of 200 scans/sec. The processing and interpretation of gather data were done by RADAN software. Because of similar dielectric values of asphalt surface and asphalt base layers, interface between these two layers could not be distinguish, so only the total thickness of asphalt layers was determinate. Obtained layers thickness is shown in Figure 4.

\subsection{FWD data}

Pavement deflection measurements carried out with Dynatest FWD in accordance with COST 336 Report [7]. Spacing between individual measurements was $100 \mathrm{~m}$ with applied impulse load of $50 \mathrm{kN}$. For each test point FWD registers pavement deflections, chainage and air temperature. Based on measured deflections elastic moduli of individual pavement layers were determinate by ELMOD6 software, separately for thickness data obtained by coring and thickness data measured by GPR.

Since only the thickness of asphalt layers were obtained by coring for purpose of backcalculation process thickness of cement treated and unbound granular base layers was taken from project documentation (design thickness). Design thickness of cement treated base layer from chainage $\mathrm{km} 75+500$ to $\mathrm{km}$ $79+800$ is $200 \mathrm{~mm}$ and from chainage $\mathrm{km} 79+800$ to $\mathrm{km} 83+000$ is $250 \mathrm{~mm}$. Design thickness of unbound granular base layer is $250 \mathrm{~mm}$ and is constant over the entire test section. Pavement layers thickness used in the backcalculaton process are shown in Figure 4. 
ROMANIAN JOURNAL

\section{OF TRANSPORT INFRASTRUCTURE}

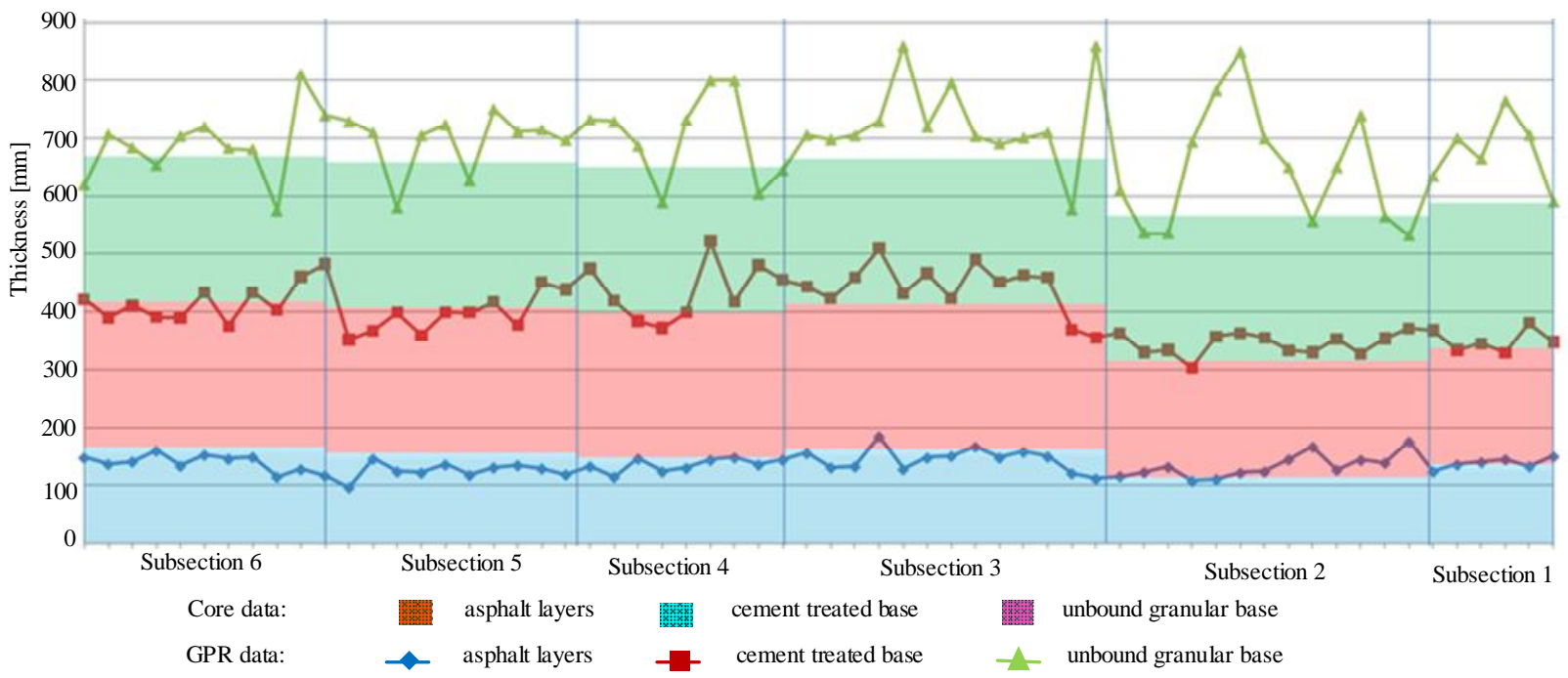

Figure 4. Pavement layers thickness used in backcalculation proces

Results of calculated elastic moduli for layers thickness determinate by core and project data as well as GPR data are shown in Figures 5 and 6 respectively.

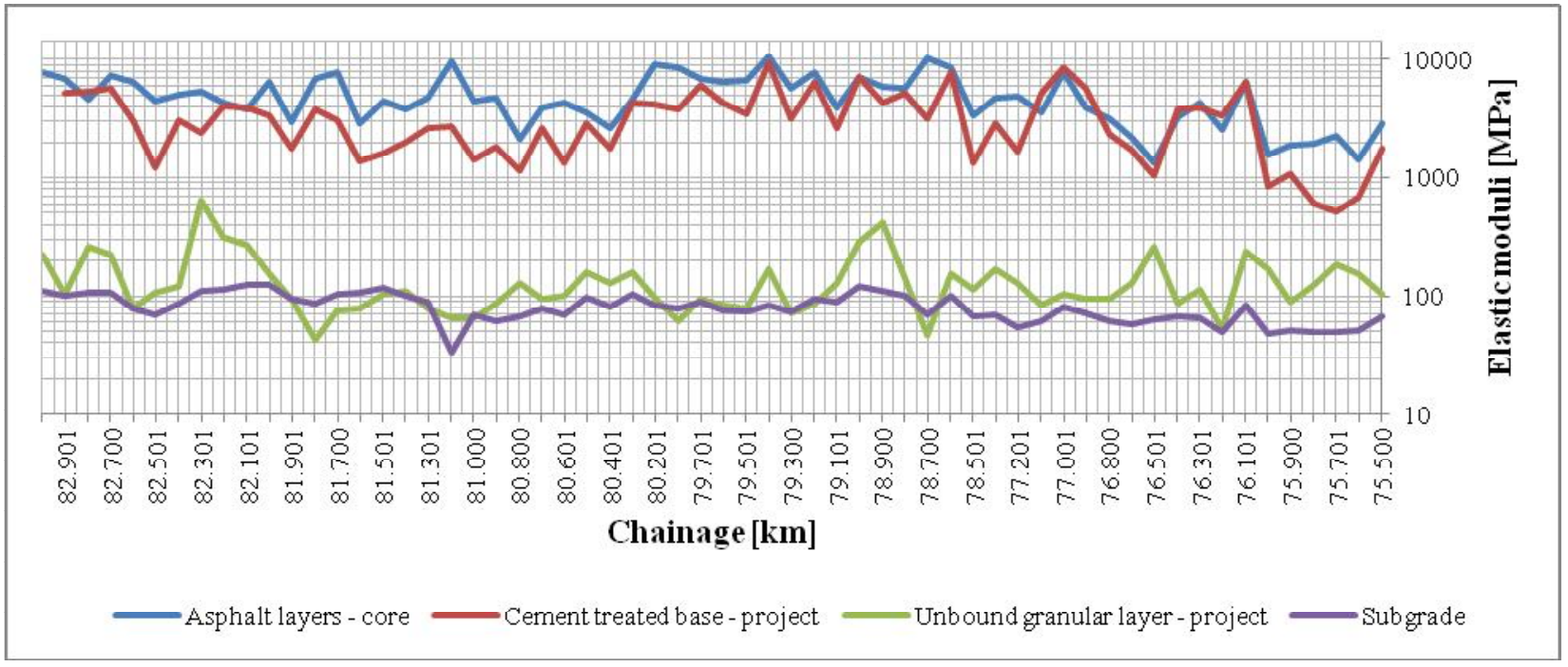

Figure 5. Calculated elastic moduli with thickness data from core and project 


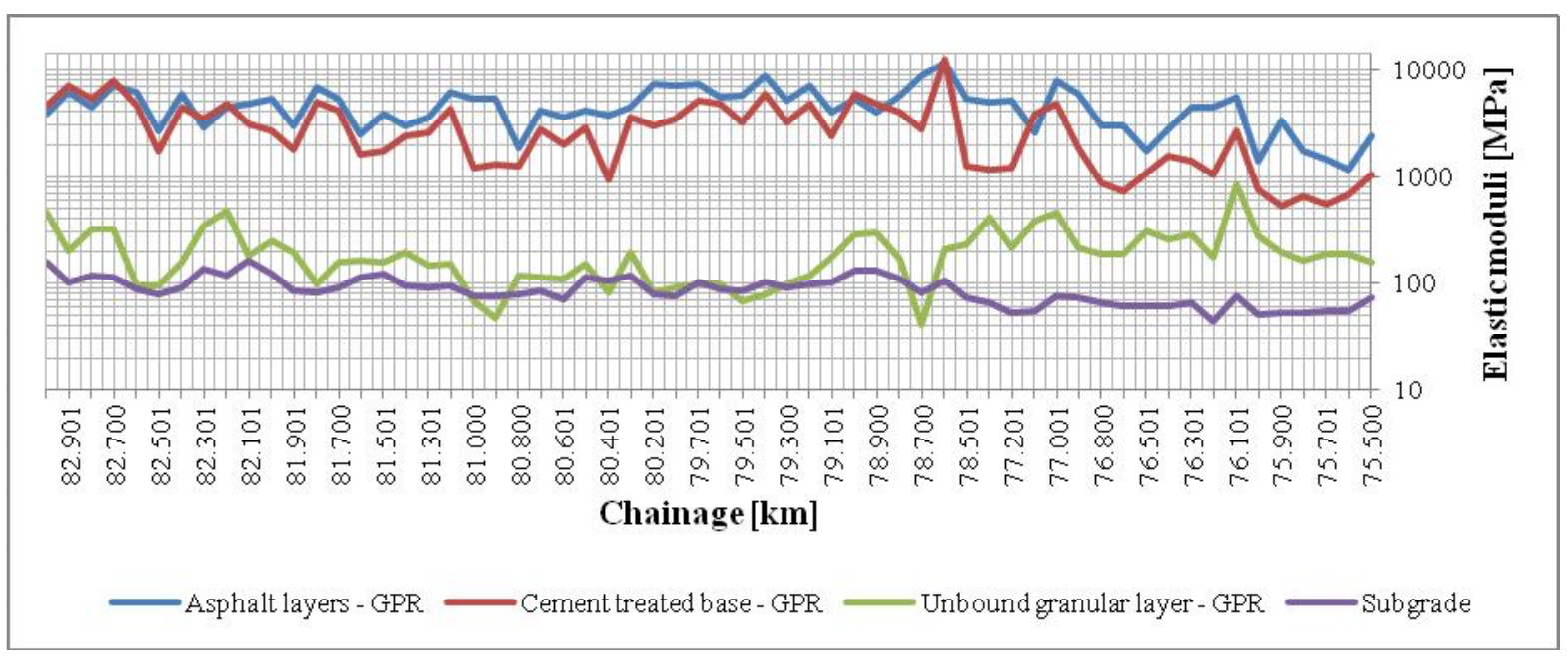

Figure 6. Calculated elastic moduli with thickness data from GPR

\section{ANALYSIS OF RESULTS}

Analysis is done for layer thickness data obtain by coring and GPR method and for layer elastic moduli calculated by using thickness data obtained as described above.

\subsection{Layer Thickness}

Total thickness of asphalt layers measured by GPR, on the entire test section, ranges from $97 \mathrm{~mm}$ to $185 \mathrm{~mm}$ with the mean value $136 \mathrm{~mm}$. Mean values of pavement layers thickness for defined subsections are show in Table 2. Verification of results of continuous measurement was conducted by comparing GPR thickness at the location of cores with thickness measured on cores. Average deviation of the results of continuous measurement was $4,5 \mathrm{~mm}$, thus confirming the accuracy of the thickness measurement by GPR. From Figure 4 it can be conclude that cores were not extracted from locations representative for considered subsection. In fact they were extracted at thickest (subsections 6, 5, 4 and 3) and thinnest (subsections 2 and 1) locations.

Table 2. Mean layers thickness data obtained by GPR for subsections

\begin{tabular}{|l|c|c|c|c|c|c|}
\cline { 2 - 8 } \multicolumn{1}{c|}{} & \multicolumn{7}{c|}{ Mean thickness [mm] } \\
\hline Homogeneous subsection & $\mathbf{1}$ & $\mathbf{2}$ & $\mathbf{3}$ & $\mathbf{4}$ & $\mathbf{5}$ & $\mathbf{6}$ \\
\hline Asphalt surface+base & 142 & 133 & 145 & 132 & 124 & 139 \\
\hline Cement treated base & 212 & 210 & 291 & 301 & 279 & 279 \\
\hline Unbound granular base & 296 & 320 & 278 & 274 & 295 & 271 \\
\hline
\end{tabular}


ROMANIAN JOURNAL

\section{OF TRANSPORT INFRASTRUCTURE}

Josipa Domitrović, Tatjana Rukavina

Application of GPR and FWD in assessing pavement bearing capacity

Thickness of cement treated base layer could not be determined by coring. Layer was completely crushed on entire test section and it was not possible to extract undisturbed samples based on which the thickness could be determined. Thickness measured by GPR ranges from $163 \mathrm{~mm}$ to $378 \mathrm{~mm}$ with mean value of $263 \mathrm{~mm}$. This data was compared with the data from project documentation. Mean value on observed sections is close to value from project documentation but it does not cover wide range of thicknesses obtained by GPR (Figure 4).

Thickness of unbound granular base layer determinate by GPR ranges from $123 \mathrm{~mm}$ to $505 \mathrm{~mm}$ and the mean value is $289 \mathrm{~mm}$. Such large range of thicknesses is result of inability to clearly distinguish the boundary between unbound granular base layer and subgrade, due to penetration of small particles of subgrade material into unbound granular material.

\subsection{Layer elastic moduli}

Elastic moduli of asphalt layers calculated for GPR thickness data range from $1200 \mathrm{MPa}$ to maximum of $11500 \mathrm{MPa}$, and for core thickness data from $1300 \mathrm{MPa}$ to $10500 \mathrm{MPa}$. On the most part of the test section, values of elastic moduli for both thickness data range from 4000 to 5000. These are characteristic values of asphalt layers elastic moduli regarding their structure, age and condition.

Elastic moduli of cement treated base layer calculated for GPR thickness data range from $500 \mathrm{MPa}$ to $12500 \mathrm{MPa}$ with the mean value of $3000 \mathrm{MPa}$, and for design thickness data from $500 \mathrm{MPa}$ to $9500 \mathrm{MPa}$ with the mean value of $3300 \mathrm{MPa}$. On the entire test section elastic moduli for both thickness data mostly vary between $1000 \mathrm{MPa}$ and $3000 \mathrm{MPa}$. This shows that layer has lost its structural integrity and its characteristics resemble unbound granular layer.

Elastic moduli of unbound granular layer on the entire test section mostly vary between $100 \mathrm{MPa}$ and $150 \mathrm{MPa}$. For project thickness data minimum value is $50 \mathrm{MPa}$ and maximum value is $650 \mathrm{MPa}$, and for GPR data minimum and maximum values are 50 and 850 respectively. This wide rane of elastic moduli indicates uneven layer quality. On some locations quality of unbound granular material is identical to quality of subgrade material.

Subgrade elastic moduli for both thickness data vary from $40 \mathrm{MPa}$ to 150 $\mathrm{MPa}$. Mean value on entire test section is $80 \mathrm{MPa}$, which corresponds to CBR of $8 \%$ and defines subgrade with good bearing capacity.

From the Table 3, it can be seen that the backcalculated layer moduli for asphalt layers and cement treated layer based on the GPR thickness data are generally lower then layer moduli calculated based on the core/design thickness 
ROMANIAN JOURNAL

\section{OF TRANSPORT INFRASTRUCTURE}

data. Elastic moduli of unbound granular base layer are on all subsections higher for GPR thickness data compared with moduli calculated for design thickness. Subgrade moduli for both thickness data are similar and put subgrade of each subsection into same bearing capacity rank.

Table 3. Calculated mean values of elastic layer moduli for subsections

\begin{tabular}{|c|l|c|c|c|c|c|c|}
\cline { 3 - 8 } \multicolumn{2}{c|}{} & \multicolumn{7}{c|}{ Elastic moduli [MPa] } \\
\hline \multirow{4}{*}{ Homogeneuos subsection } & $\mathbf{1}$ & $\mathbf{2}$ & $\mathbf{3}$ & $\mathbf{4}$ & $\mathbf{5}$ & $\mathbf{6}$ \\
\hline \multirow{2}{*}{} & Asphalt surface+base & 1786 & 3935 & 6229 & 4167 & 4006 & 4657 \\
\cline { 2 - 8 } & Cement treated base & 690 & 1554 & 4030 & 1897 & 2677 & 4152 \\
\cline { 2 - 8 } & Unbound granular base & 190 & 292 & 126 & 99 & 153 & 229 \\
\cline { 2 - 8 } & Subgrade & 57 & 63 & 97 & 87 & 96 & 113 \\
\hline \multirow{3}{*}{} & Asphalt surface+base & 1936 & 3650 & 6657 & 4088 & 4736 & 5443 \\
\cline { 2 - 8 } & Cement treated base & 834 & 3302 & 4364 & 2159 & 2326 & 4049 \\
\cline { 2 - 8 } & Unbound granular base & 133 & 118 & 115 & 109 & 87 & 194 \\
\cline { 2 - 8 } & Subgrade & 52 & 65 & 86 & 78 & 102 & 99 \\
\hline
\end{tabular}

\section{CONCLUSIONS}

Estimation of pavement bearing capacity is first step necessary to calculate pavement remaining life and is main input parameter for most pavement reinforcement design methods. Contemporary techniques for estimation of pavement bearing capacity include measurement of pavement deflections by FWD device and interpretation of so collected data by backcalculation process to determine layers elastic moduli. Application of this techniques enabled distance from known empirical pavement reinforcement design methods. By knowing the in situ elastic moduli of individual layer it is possible to optimize calculation of pavement remaining life and pavement reinforcement design.

Main input parameters in backcalculation process are pavement deflections and layer thickness which can be determinate by coring (localized) or measured by GPR device (continuous). Comparing values of elastic moduli obtained through backcalculation process by ELMOD6 software for two cases, first in which layers thickness was obtained by coring and second in which layers thickness was obtained by GPR, it was concluded that there are certain 
differences in calculated elastic moduli values but they are not so significant to discard values obtain based on thickness data from cores.

For design purposes, if the GPR device is not available, it is possible to use thickness data from cores. However, since there is a tendency in reinforcement projects to apply recycling methods and use recycled materials, knowing the continuous thickness of asphalt layers is essential in order to determine the optimum thickness available for milling and thus achieve optimization of recycling process.

\section{ACKNOWLEDGMENTS}

This study is a contribution to the EU funded COST Action TU1208, "Civil Engineering Applications of Ground Penetrating Radar".

\section{REFERENCES}

[1]. J. WENZLICK, T. SCULLONO, K.R. MASER: "High Accuracy Pavement Thickness Measurement Using Ground Penetrating Radar", Missouri Department of Transportation Research, Development and Technology Division, February 1999.

[2]. M.OŽBOLT, T. RUKAVINA, J.DOMITROVIĆ: “Comparison of pavement layer thickness measured by GPR and conventional methods", The Baltic Journal of Road and Bridge engineering, vol.7, no.1, 2012.

[3]. T. SATTENKETO: "Timo, Electrical properties of road materials and subgrade soils and the use of Ground Penetrating Radar in traffic infrastructure surveys", Faculty of Science, Department of Geosciences, University of Oulu, Finland, 2006.

[4]. S. FONTUL: "Structural Evaluation of Flexible Pavements Using Non-Destructive Tests", PhD thesis, LNEC, Lisabon, Portugal, 2004.

[5]. F.ZHOU, T. SCULLION: “Guidelines for evaluation of existing pavements for HMA overlay”, Report 0-5123-2, Texas Transportation Institute, Texas, November 2006.

[6]. S. ALAVI, J.F. LECATES, M.P. TAVARES: “Falling Weight Deflectometer Usage, A Synthesis of Highway Practice”, NCHRP Synthesis 381, Sierra Transportation Engineers, Inc.Reno, Nevada, 2008.

[7]. "Use of Falling Weight Deflectometers in Pavement Evaluation", COST 336, European Commission, Directorate General Transport, April 2005. 